Check for updates

Cite this: RSC Adv., 2017, 7, 29271

Received 16th May 2017

Accepted 31st May 2017

DOI: $10.1039 / \mathrm{c} 7 \mathrm{ra05544g}$

rsc.li/rsc-advances

\section{Subphthalocyanine-based porous organic polymers $\uparrow$}

\author{
Grace M. Eder, Benjamin R. Walker and Psaras L. McGrier (DD* \\ Subphthalocyanines (SubPcs) are bowl-shaped chromophores that possess optical properties desirable for \\ organic electronics. Herein, we present the synthesis and characterization of two SubPc-based porous \\ organic polymers (POPs). The SubPc-POPs exhibit respectable surface areas, and Q-bands that are \\ significantly red-shifted in the solid-state.
}

Porous organic polymers (POPs) are a diverse group of materials that have garnered interest for their lightweight, highly porous architectures covering a wide range of applications including catalysis ${ }^{1-3}$ sensing,${ }^{4-7}$ and separations. ${ }^{8-11}$ Within the broader umbrella of POPs ${ }^{12}$ exist many subgroups, including but not limited to porous aromatic frameworks (PAFs), ${ }^{13}$ porous polymer networks (PPNs), ${ }^{14-16}$ and conjugated microporous polymers (CMPs). ${ }^{17}$ The incorporation of $\pi$-conjugated monomers allows for tuning of the bulk properties of the polymer and increases their potential utility in devices. Inclusion of chromophores with extended $\pi$-systems, such as borondipyrromethenes (BODIPYs), porphyrins and phthalocyanines (Pcs), into porous polymers has allowed for the creation of materials amenable to optoelectronic applications, such as photocatalysis, ${ }^{18,19}$ organic light emitting diodes (OLEDs), ${ }^{20,21}$ and photovoltaic materials. ${ }^{22-24}$ Despite the incorporation of Pcs into linear polymers ${ }^{25-27}$ and two-dimensional (2D) porous polymers, ${ }^{28-36}$ no porous material to date has incorporated subphthalocyanine (SubPc) monomers.

SubPcs, which are smaller homologues of Pcs, contain three $\mathrm{N}$-fused 1,3-diiminoisoindole units that are chelated to a boron atom with a protruding axial ligand. Our inspiration to pursue the $\mathrm{C}_{3}$-symmetric bowl-shaped SubPc monomer evolved from its non-planar $14 \pi$-electron conjugated structure which could provide access to unique porous polymers with small Stokes shifts and low reorganizational energies. These features have enabled SubPcs to achieve respectable power conversion efficiencies as both donor and acceptor materials in small molecule-based organic photovoltaic devices (OPVs). ${ }^{37-40}$ However, 2D polymeric materials based on SubPcs are essentially unknown, with the exception of their inclusion into selfassembled SubPc films. ${ }^{41-43}$ While these thin layer 2D systems could be useful for information storage or liquid crystalline technologies, only slow progress has been made in this

Department of Chemistry \& Biochemistry, The Ohio State University, $100 \mathrm{~W} .18^{\text {th }}$ Ave., Columbus, Ohio 43210, USA. E-mail: mcgrier.1@osu.edu

$\dagger$ Electronic supplementary information (ESI) available. See DOI: $10.1039 / \mathrm{c} 7 \mathrm{ra05544g}$ direction. Polymers successfully incorporating SubPc monomers are rare and only a few examples of styrene copolymers with pendant SubPc groups have been reported. ${ }^{44,45}$ However, this post polymerization strategy was problematic, and did not afford a high incorporation of SubPc into the polymeric material. It also lacks the added functionality of porosity as a way to interact with guest molecules. Our strategy opted for a mild cocondensation reaction to form a boronate ester linkage, which can be constructed without an external catalyst at moderate temperatures, while simultaneously incorporating the SubPc monomeric units into a covalently linked polymeric network. Such nonplanar polymeric systems incorporating SubPcs have yet to be reported.

Herein, we present the synthesis and characterization of SubPc-POP 1 and 2 (Scheme 1). The POPs were constructed by reacting SubPcs $\mathbf{2 b}$ and $\mathbf{3 b}$ (Fig. 1) with 1,4-benzene diboronic acid (BDBA) in a $1: 1(\mathrm{v} / \mathrm{v})$ mixture of dioxane and mesitylene to yield dark purple solids. These optimal reaction conditions were obtained by thoroughly screening solvent ratios and reaction temperatures (Table $1, \mathrm{ESI} \dagger$ ). It should be noted that our initial polymer design aimed to utilize $\mathbf{1 b}$ to form a $2 \mathrm{D}$ POP with axial chloride ligands (Fig. 1). However, compound $\mathbf{1 b}$ and the TIPS-protected 1a were highly sensitive to acidic or basic environments and ambient light, which made them difficult to isolate in large quantities. We believe that this rapid

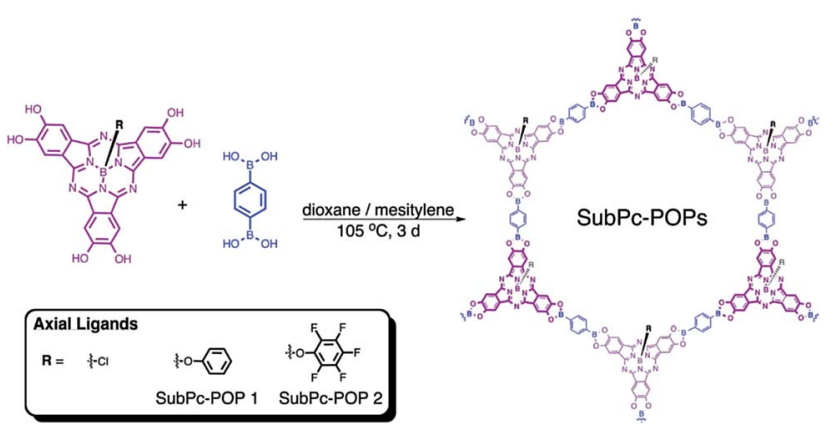

Scheme 1 Synthesis of the SubPc-POPs. 


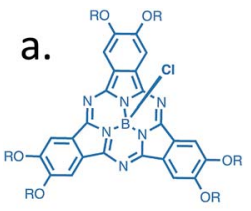

1a: $R=$ TIPS $1 \mathrm{~b}: \mathrm{R}=\mathrm{H}$

b.

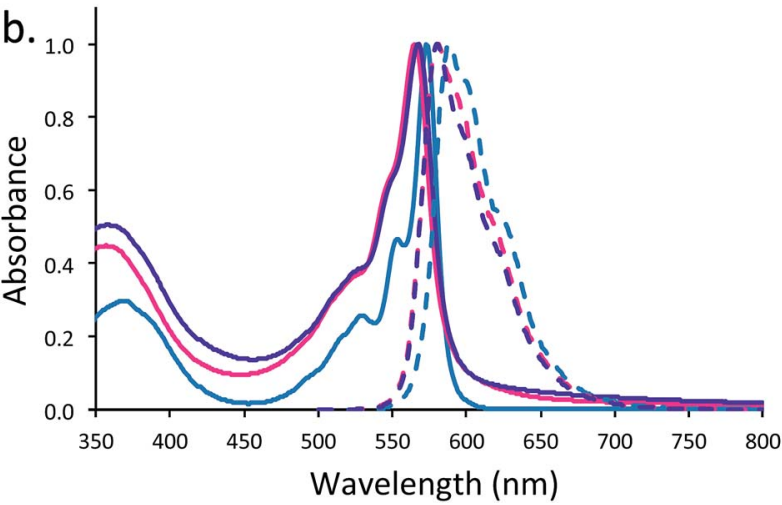

Fig. 1 (a) Structures of TIPS- and hexahydroxyl-substituted SubPc monomers. (b) UV-Vis (solid line) and fluorescence spectra (dotted line) of hexahydroxyl-substituted SubPcs $1 b$ (blue), 2b (pink), and 3b (purple) in acetone.

degradation is mostly due to the relatively labile $\mathrm{B}-\mathrm{Cl}$ bond, ${ }^{46}$ and the strongly electron-donating nature of the peripheral hydroxyl groups. As a consequence, we exchanged the axial chlorine atom for a phenoxy substituent in a one-pot synthetic procedure (pg. S4, ESI $\dagger$ ). Interestingly, compounds $2 \mathbf{a}$ and $\mathbf{2 b}$ proved to be more chemically stable than the $\mathbf{1 b}$ counterpart. In an effort to investigate the effects of axial substitution on the solid-state packing of the bulk material, we also synthesized 3a and $\mathbf{3 b}$ by replacing the chlorine atom with a pentafluorophenoxy substituent.

The SubPc-POPs were characterized by Fourier transform infrared (FT-IR) and ${ }^{13} \mathrm{C}$ cross-polarization magic angle spinning (CP-MAS) spectroscopies. The FT-IR spectra of SubPc-POP 1 and 2 both displayed the characteristic $\mathrm{C}=\mathrm{N}$ stretching mode of the SubPc monomer at 1465 and $1468 \mathrm{~cm}^{-1}$, and the B-O stretch from the axial ligands at 1046 and $1039 \mathrm{~cm}^{-1}$, respectively (Fig. S7 \& S8, ESI $\dagger$ ). The B-O stretching modes at 1347 and $1352 \mathrm{~cm}^{-1}$ are indicative of the boronate ester linkages for SubPc-POP 1 and 2, respectively. The connectivity of the SubPcPOPs was verified by solid-state ${ }^{13} \mathrm{C}$ CP-MAS NMR, which contained all of the expected resonances for the materials (Fig. S11 \& S12, ESI $\dagger$ ). In addition, the incorporation of the SubPc $\mathbf{2 b}$ and 3b monomers was further confirmed by ${ }^{1} \mathrm{H}$ NMR digestion experiments (Fig. S26 \& S27, ESI†). Thermogravimetric analysis (TGA) revealed that SubPc-POP 1 maintains $\sim 85 \%$ of its weight up to $400{ }^{\circ} \mathrm{C}$ (Fig. S13, ESI $\dagger$ ). In contrast, SubPc-POP 2 failed to give conclusive TGA data at high temperatures. Scanning electron microscopy (SEM) revealed two different bulk phase morphologies for both SubPc-POPs (Fig. 2).

The permanent porosities of the SubPc-POPs were evaluated by nitrogen gas adsorption isotherms at $77 \mathrm{~K}$ (Fig. 3). SubPcPOP 1 and 2 both exhibit reversible type I isotherms with

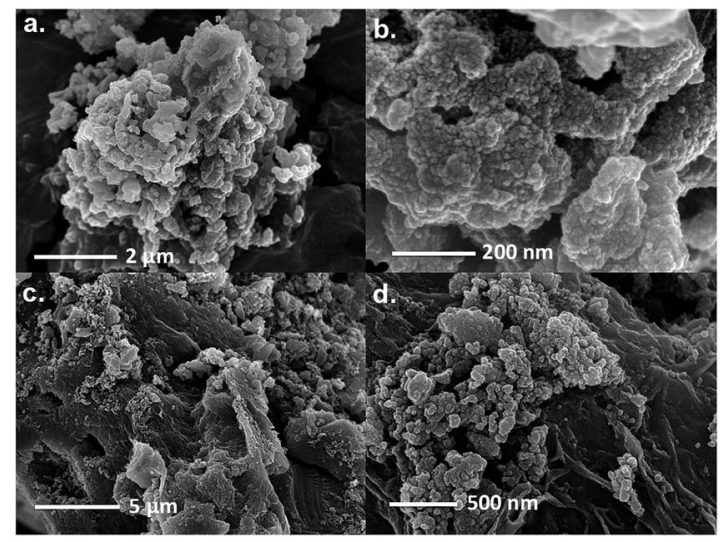

Fig. 2 SEM Images of SubPc-POP 1 ( $a$ and b) and SubPc-POP 2 (c and d) at different magnifications.

a small but noticeable hysteresis. Application of the BrunauerEmmett-Teller (BET) model over the low-pressure region (0.001-0.005 $\left.<P / P_{0}<0.13-0.20\right)$ provided surface areas of 231 and $93 \mathrm{~m}^{2} \mathrm{~g}^{-1}$ for SubPc-POP 1 and 2, respectively. Nonlocal density functional theory (NLDFT) was used to estimate the pore size distributions of SubPc-POP 1 and 2 yielding values of 1.7 and $1.5 \mathrm{~nm}$, respectively, which is indicative of the microporosity of the materials. The total pore volumes were calculated from the single point value of $P / P_{0}=0.90$ to provide values of 0.131 and $0.087 \mathrm{~cm}^{3} \mathrm{~g}^{-1}$ for SubPc-POP 1 and 2, respectively.

Powder X-ray diffraction (PXRD) analysis of the SubPc-POPs revealed amorphous materials with no apparent long-range
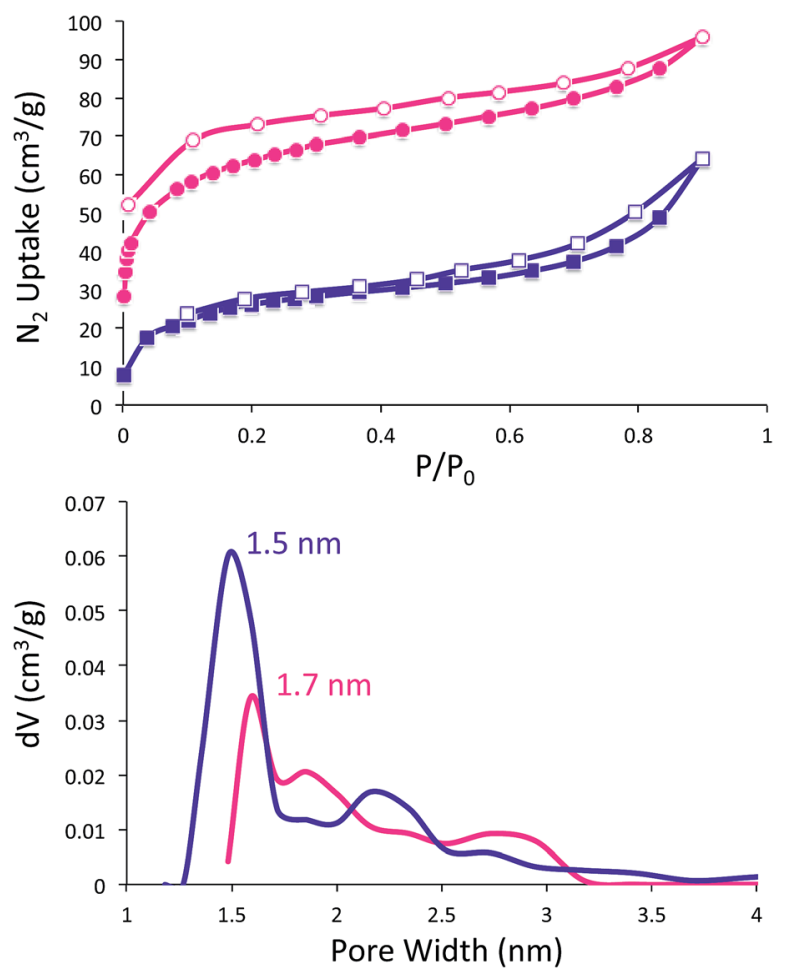

Fig. 3 Nitrogen adsorption/desorption isotherms (top), and NLDFT pore size distributions (bottom) for SubPc-POP 1 (pink) and SubPcPOP 2 (purple). 
order (Fig. S9 \& S10, ESI $\dagger$ ). Initially, we anticipated that a SubPcPOP substituted with chlorine atoms in the axial position would exhibit a concave-to-ligand solid-state packing motif similar to the trans binuclear SubPc systems previously reported by Kobayashi and Durfee. ${ }^{47}$ However, these polymeric systems could not be constructed due to the chemical instability of $\mathbf{1 b}$. As a consequence, we believe the larger axial phenoxy and pentafluorophenoxy substitutents of $\mathbf{2 b}$ and $\mathbf{3 b}$ prevent the monomers from forming the concave-to-ligand stacking interactions, and instead lead to the formation of disordered POPs.

The 14- $\pi$ electron core of SubPcs is capable of absorbing and emitting radiation in the visible spectrum. Normalized UV-Vis and fluorescence spectra of dilute solutions $\left(2 \times 10^{-5} \mathrm{M}\right)$ of $\mathbf{1 b}, \mathbf{2 b}$, and $\mathbf{3 b}$ in acetone are shown in Fig. $\mathbf{1 b}$. The absorption maxima range from 566 to $574 \mathrm{~nm}$ and are attributed to the typical Q-band absorption peaks for SubPcs. Each absorption spectrum contains distinct shoulder peaks ranging from 547 to $553 \mathrm{~nm}$. The weak high energy absorption bands at $\sim 368 \mathrm{~nm}$ are possibly attributed to an $n-\pi^{*}$ transition between the lone pair of the oxygen atoms and the peripheral aromatic ring. ${ }^{48}$ The fluorescence spectra of $\mathbf{1 b}, \mathbf{2} \mathbf{b}$ and $\mathbf{3 b}$ revealed emission peaks at $\lambda_{\max } 587,581$ and $580 \mathrm{~nm}$, respectively. In addition, broad shoulders ranging from 616 to $624 \mathrm{~nm}$, which reflected their corresponding absorption spectra, accompanied each emission spectrum.

In contrast to the monomers in solution, SubPc-POPs 1 and 2 did not exhibit any unique fluorescent properties, and were fully quenched in the solid-state. We believe that the disordered packing of the material leads to aggregation-caused quenching (ACQ) due to the rapid thermal decay of the photoexcited state. ${ }^{\mathbf{9}}$ However, diffuse reflectance spectra of SubPc-POP 1 and 2 revealed that both materials display peak absorption bands at $\sim 583$ and $581 \mathrm{~nm}$, respectively, along with weak bands that extend into the near infrared part of the spectrum (Fig. 4). It should be noted that these absorption maxima are considerably red-shifted by $\sim 50-60 \mathrm{~nm}$ compared to the powders of $2 \mathbf{b}\left(\lambda_{\max }\right.$ $=530 \mathrm{~nm})$ and $3 \mathbf{b}\left(\lambda_{\max }=520 \mathrm{~nm}\right)$ (Fig. S24 \& S25, ESI $\left.\dagger\right)$, which suggest the formation of disordered J-aggregates in the solidstate.

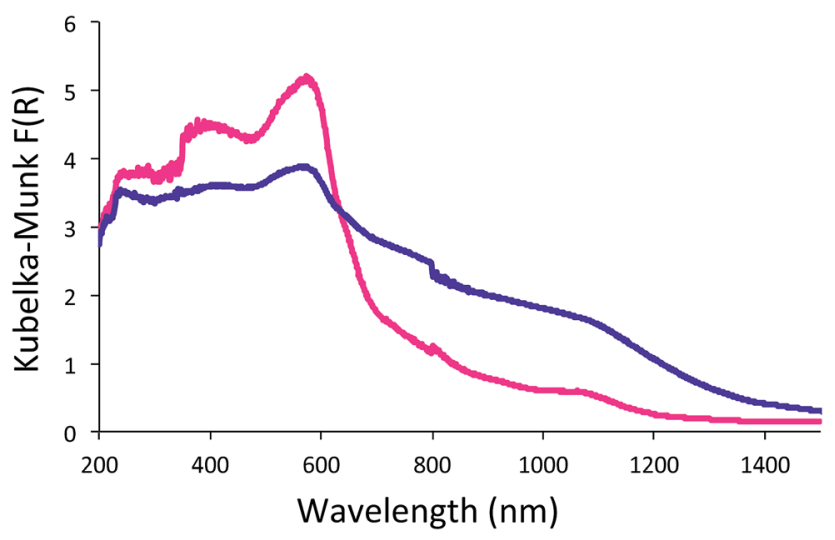

Fig. 4 Diffuse reflectance of SubPc-POP 1 (pink) and SubPc-POP 2 (purple).

\section{Conclusions}

In conclusion, we have demonstrated that hexahydroxylsubstituted SubPc monomers can be used to construct nonplanar POPs with respectable pore sizes and surface areas. The diffuse reflectance spectra show that the absorption properties of the SubPc-POPs are significantly red-shifted compared to the monomeric SubPc units. Future studies could involve utilizing axial-substitution to tune the bulk properties of the material in the solid-state. ${ }^{\mathbf{5 0 , 5 1}}$ Such investigations could yield functional nonplanar SubPc-based porous polymers with unique optoelectronic properties.

\section{Acknowledgements}

P. L. M. acknowledges the National Science Foundation (NSF) and Georgia Tech Facilitating Academic Careers in Engineering and Science (GT-FACES) for a Career Initiation Grant, and funding from The Ohio State University.

\section{Notes and references}

1 Q. Q. Dang, Y. F. Zhan, X. M. Wang and X. M. Zhang, ACS Appl. Mater. Interfaces, 2015, 7, 28452-28458.

2 Y. Peng, T. Ben, Y. Jia, D. Yang, H. Zhao, S. Qiu and X. Yao, J. Phys. Chem. C, 2012, 116, 25694-25700.

3 S. N. Talapaneni, O. Buyukcakir, S. H. Je, S. Srinivasan, Y. Seo, K. Polychronopoulou and A. Coskun, Chem. Mater., 2015, 27, 6818-6826.

4 X. Liu, Y. Xu and D. Jiang, J. Am. Chem. Soc., 2012, 134, 87388741.

5 J. L. Novotney and W. R. Dichtel, ACS Macro Lett., 2013, 2, 423-426.

6 A. T. E. Vilian, P. Puthiaraj, C. H. Kwak, S. K. Hwang, Y. S. Huh, W. S. Ahn and Y. K. Han, ACS Appl. Mater. Interfaces, 2016, 8, 12740-12747.

7 J. S. Yang and T. M. Swager, J. Am. Chem. Soc., 1998, 120, 11864-11873.

8 A. Ahmed, Z. Xie, K. Konstas, R. Babarao, B. D. Todd, M. R. Hill and A. W. Thornton, Langmuir, 2014, 30, 1462114630.

9 C. H. Lau, K. Konstas, A. W. Thornton, A. C. Y. Liu, S. Mudie, D. F. Kennedy, S. C. Howard, A. J. Hill and M. R. Hill, Angew. Chem., Int. Ed., 2015, 54, 2669-2673.

10 B. Li, Y. Zhang, R. Krishna, K. Yao, Y. Han, Z. Wu, D. Ma, Z. Shi, T. Pham, B. Space, J. Liu, P. K. Thallapally, J. Liu, M. Chrzanowski and S. Ma, J. Am. Chem. Soc., 2014, 136, 8654-8660.

11 X. Zhu, C. Tian, S. M. Mahurin, S.-H. Chai, C. Wang, S. Brown, G. M. Veith, H. Luo, H. Liu and S. Dai, J. Am. Chem. Soc., 2012, 134, 10478-10484.

12 Q. Chen, M. Luo, T. Wang, J. X. Wang, D. Zhou, Y. Han, C. S. Zhang, C. G. Yan and B. H. Han, Macromolecules, 2011, 44, 5573-5577.

13 L. Li, K. Cai, P. Wang, H. Ren and G. Zhu, ACS Appl. Mater. Interfaces, 2015, 7, 201-208. 
14 P. Kuhn, A. Thomas and M. Antonietti, Macromolecules, 2009, 42, 319-326.

15 W. Lu, D. Yuan, J. Sculley, D. Zhao, R. Krishna and H.-C. Zhou, J. Am. Chem. Soc., 2011, 133, 18126-18129.

16 W. Lu, D. Yuan, D. Zhao, C. I. Schilling, O. Plietzsch, T. Muller, S. Bräse, J. Guenther, J. Blümel, R. Krishna, Z. Li and H. C. Zhou, Chem. Mater., 2010, 22, 5964-5972.

17 L. Chen, Y. Honsho, S. Seki and D. Jiang, J. Am. Chem. Soc., 2010, 132, 6742-6748.

18 M. Liras, M. Iglesias and F. Sánchez, Macromolecules, 2016, 49, 1666-1673.

19 J. Luo, X. Zhang and J. Zhang, ACS Catal., 2015, 5, 22502254.

20 B. Bonillo, R. S. Sprick and A. I. Cooper, Chem. Mater., 2016, 28, 3469-3480.

21 J. Liu, K. K. Yee, K. K. W. Lo, K. Y. Zhang, W. P. To, C. M. Che and Z. Xu, J. Am. Chem. Soc., 2014, 136, 2818-2824.

22 J. Guo, Y. Xu, S. Jin, L. Chen, T. Kaji, Y. Honsho, M. A. Addicoat, J. Kim, A. Saeki, H. Ihee, S. Seki, S. Irle, M. Hiramoto, J. Gao and D. Jiang, Nat. Commun., 2013, 4, 2736-2744.

23 M. Dogru, M. Handloser, F. Auras, T. Kunz, D. Medina, A. Hartschuh, P. Knochel and T. Bein, Angew. Chem., Int. Ed., 2013, 52, 2920-2924.

24 C. Gu, N. Huang, Y. Chen, L. Qin, H. Xu, S. Zhang, F. Li, Y. Ma and D. Jiang, Angew. Chem., Int. Ed., 2015, 54, 13594-13598.

25 B. N. Achar, G. M. Fohlen and J. A. Parker, J. Polym. Sci., Polym. Chem. Ed., 1982, 20, 2773-2780.

26 G. C. Bryant, M. J. Cook, S. D. Haslam, R. M. Richardson, T. G. Ryan and A. J. Thornec, J. Mater. Chem., 1994, 4, 209216.

27 M. Kimura, K. Wada, K. Ohta, K. Hanabusa, H. Shirai and N. Kobayashi, Macromolecules, 2001, 34, 4706-4711.

28 E. L. Spitler and W. R. Dichtel, Nat. Chem., 2010, 2, 672-677. 29 X. Ding, L. Chen, Y. Honsho, X. Feng, O. Saengsawang, J. Guo, A. Saeki, S. Seki, S. Irle, S. Nagase, V. Parasuk and D. Jiang, J. Am. Chem. Soc., 2011, 133, 14510-14513.

30 X. Ding, J. Guo, X. Feng, Y. Honsho, J. Guo, S. Seki, P. Maitarad, A. Saeki, S. Nagase and D. Jiang, Angew. Chem., Int. Ed., 2011, 50, 1289-1293.

31 X. Ding, X. Feng, A. Saeki, S. Seki, A. Nagai and D. Jiang, Chem. Commun., 2012, 48, 8952-8954.

32 S. Jin, X. Ding, X. Feng, M. Supur, K. Furukawa, S. Takahashi, M. Addicoat, M. E. El-Khouly, T. Nakamura, S. Irle,
S. Fukuzumi, A. Nagai and D. Jiang, Angew. Chem., Int. Ed., 2013, 52, 2017-2021.

33 V. S. P. K. Neti, X. Wu, M. Hosseini, R. A. Bernal, S. Deng and L. Echegoyen, CrystEngComm, 2013, 15, 7157-7160.

34 L. Chen, K. Furukawa, A. Nagai, T. Nakamura, Y. Dong and D. Jiang, J. Am. Chem. Soc., 2014, 9806-9809.

35 X. Ding and B. Han, Angew. Chem., Int. Ed., 2015, 54, 65366539.

36 X. Feng, X. Ding and D. Jiang, Chem. Soc. Rev., 2012, 41, 6010-6022.

37 K. L. Mutolo, E. I. Mayo, B. P. Rand, S. R. Forrest and M. E. Thompson, J. Am. Chem. Soc., 2006, 128, 8108-8109.

38 B. Verreet, B. P. Rand, D. Cheyns, A. Hadipour, T. Aernouts, P. Heremans, A. Medina, C. G. Claessens and T. Torres, Adv. Energy Mater., 2011, 1, 565-568.

39 G. E. Morse and T. P. Bender, ACS Appl. Mater. Interfaces, 2012, 4, 5055-5068.

40 K. Cnops, G. Zango, J. Genoe, P. Heremans, M. V. MartínezDíaz, T. Torres and D. Cheyns, J. Am. Chem. Soc., 2015, 137, 8991-8997.

41 M. Trelka, A. Medina, D. Ecija, C. Urban, O. Gröning, R. Fasel, J. M. Gallego, C. G. Claessens, R. Otero, T. Torres and R. Miranda, Chem. Commun., 2011, 47, 9986-9988.

42 X. Liang, T. Chen, Y.-S. Jung, Y. Miyamoto, G. Han, S. Cabrini, B. Ma and D. L. Olynick, ACS Nano, 2010, 4, 2627-2634.

43 H. Yanagi, K. Ikuta, H. Mukai and T. Shibutani, Nano Lett., 2002, 2, 951-955.

44 B. H. Lessard and T. P. Bender, Macromol. Rapid Commun., 2013, 34, 568-573.

45 B. H. Lessard, K. L. Sampson, T. Plint and T. P. Bender, J. Polym. Sci., Part A: Polym. Chem., 2015, 53, 1996-2006.

46 S. Remiro-Buenamañana, A. Díaz-Moscoso, D. L. Hughes, M. Bochmann, G. J. Tizzard, S. J. Coles and A. N. Cammidge, Angew. Chem., Int. Ed., 2015, 54, 7510-7514. 47 T. Fukuda, J. R. Stork, R. J. Potucek, M. M. Olmstead, B. C. Noll, N. Kobayashi and W. S. Durfee, Angew. Chem. Int. Ed., 2002, 41, 2565-2568.

48 I. Sánchez-Molina, C. G. Claessens, B. Grimm, D. M. Guldi and T. Torres, Chem. Sci., 2013, 4, 1338-1344.

49 S. Dalapati, E. Jin, M. Addicoat, T. Heine and D. Jiang, J. Am. Chem. Soc., 2016, 138, 5797-5800.

50 J. Guilleme, D. González-Rodríguez and T. Torres, Angew. Chem., Int. Ed., 2011, 50, 3506-3509.

51 J. D. Virdo, Y. H. Kawar, A. J. Lough and T. P. Bender, CrystEngComm, 2013, 15, 3187-3199. 